\title{
Inflammatory periapical cyst decompression. case report with follow-up of five years
}

\begin{abstract}
Radicular cysts are constantly found in routine dental practice, alternating in size and location. For large cysts, the recommended treatment is surgical decompression, which may be followed or not by enucleation of the cystic epithelium. This article reports the case of a 36 year old female, who presented herself at the Department of Oral and Maxillofacial Surgery and Traumatology (CTBMF), School of Dentistry, Pontifical Catholic University of Rio Grande do Sul (PUCRS) presenting an extensive radicular cyst involving teeth 11,12 and 13 , extending posteriorly, limited at the posterior wall of the maxillary sinus, having as origin infection on tooth 12 . The transalveolar decompression technique was performed, by means of a mechanical device, after removal of tooth 12 . One year and nine months after the decompression procedure, complete regression of the lesion was observed, with no bone sequelae and with maintenance of the results over five years of clinical and radiographic follow up.
\end{abstract}

Keywords: Radicular cyst, treatment, decompression
Volume 9 Issue 3 - 2018

\author{
Ricardo Giacomini De Marco,' Natália \\ Batista Daroit, ${ }^{2}$ Ricardo Augusto Conci,' \\ Fernando de Oliveira Andriola,' Leonardo \\ Matos Santolim Zanettini,' Rogerio Miranda \\ Pagnoncelli,' Guilherme Genehr Fritscher' \\ 'Department of Oral and Maxillofacial Surgery, Pontifical \\ Catholic University of Rio Grande do Sul, Brazil \\ ${ }^{2}$ Department of Oral Pathology, Federal University of Rio \\ Grande do Sul, Brazil
}

\begin{abstract}
Correspondence: Ricardo Giacomini de Marco, Doctoral Student, Oral and Maxillofacial Surgery, Pontifical Catholic University of Rio Grande do Sul, St. Martins de Lima, 57/406, Porto Alegre/RS, CEP: $91520-000$, Brazil, Tel +55 51996486596 , Email ricardogdemarco@hotmail.com
\end{abstract}

Received: June 04, 2018 | Published: June 08, 2018

\section{Introduction}

The Dental Surgeon often encounters small granulomas and cysts of periapical origin during clinical care. Definitive treatment of these generally consists of endodontic treatment or tooth extraction, with curettage of the lesions. When more complex cases are encountered, which present large lesions, such as the one reported in this work, we can use conservative treatments that ensure excellent results over time minimizing postoperative morbidity and unwanted disorders such as extensive bone defects. Radicular cysts are characterized by a capsule of fibrous connective tissue lined by epithelium with a lumen containing fluids and cell debris. Theoretically, as the epithelium desquamates into the cyst, the protein content increases. The liquid enters the lumen in an attempt to equalize the osmotic pressure and slow growth occurs. It is histologically characterized by a stratified squamous epithelium lining. Its epithelial source are, commonly, epithelial cell rests of Malassez, but may also be related to the crevicular epithelium, the sinus lining, or the epithelial lining of the fistulous tracts. They represent 7 to $54 \%$ of periapical radiolucencies. They do not present clinical symptoms, unless there is acute inflammatory exacerbation. Furthermore, if the cyst reaches a large size, swelling and light sensitivity can be observed, which may cause mobility and displacement of adjacent teeth. Radiographically it is characterized by a radiolucent, round or oval lesion bordered by a well defined radiopaque line. ${ }^{1}$ Among the conservative treatments, marsupialization and decompression can be cited, which refer to the creation of a surgical window in the cyst wall, evacuating its contents and maintaining the continuity between the cyst and the oral cavity. Only the fragment to access the interior of the cyst is removed, which is then sent to histopathological examination. The remaining cyst lining should be left in situ. This procedure decreases the intracystic pressure and promotes its reduction and bone fill. ${ }^{2}$ In case of very large lesions, due to the possibility of undesirable consequences arising from surgical enucleation, procedures such as marsupialisation or decompression are indicated. ${ }^{3}$ The benefits of marsupialisation and decompression include gradual decrease in the cystic cavity, preservation of the oral tissues, maintenance of pulp vitality and prevention of dental extractions. Surgical damage to important anatomical structures, such as the lower alveolar nerve, maxillary sinus, and nasal cavity, can also be avoided. ${ }^{4}$ The purpose of this study is to report a case of cystic decompression in the maxilla, which succeeded without complementary treatments (enucleation) and has been followed up for about five years.

\section{Case report}

Patient JMP, female, 36 years old, was referred to the CTBMF sector of the Faculty of Dentistry of PUCRS for evaluation of a large radiolucent lesion, with well defined boundaries in the maxilla, involving teeth 11,12 and 13, extending posteriorly, limited at the posterior wall of the maxillary sinus, having as cause infection of tooth 12 (Figure 1). Extraction of tooth 12 and incisional biopsy of the capsule of the lesion were performed, and a transalveolar decompression device (surgical aspirator tip) installed (Figure 2), being inserted in the socket derived from the extraction of tooth 12 , drilled on the sides for fastening with two sutures using 4-0 Nylon thread. The patient was instructed to perform irrigation using $0.9 \%$ saline solution twice a day. To conduct the saline to the cystic cavity a $10 \mathrm{~mL}$ syringe with a 22 Gauge needle was used. Endodontic treatment of teeth 11 and 13, involved in the lesion, was also performed. Histopathological examination of the lesion confirmed the clinical diagnosis of Inflammatory Radicular Cyst. After five months of decompression, significant regression of the lesion was observed (Figure 3), thus removal of the transalveolar drain was performed. One year and nine months after the intervention, complete regression of the lesion and bone neoformation were radiographically observed (Figure 4), which was maintained during the five years of follow up (Figure 4), (Figure 5) and (Figure 6). 


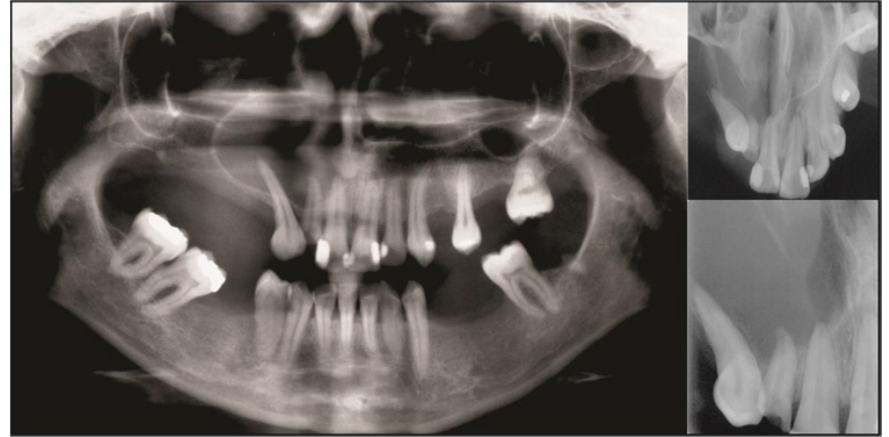

Figure I Initial panoramic, occlusal and periapical radiograph showing Intra bone cyst involving the dental elements II, I 2 and I3, extending to posterior.

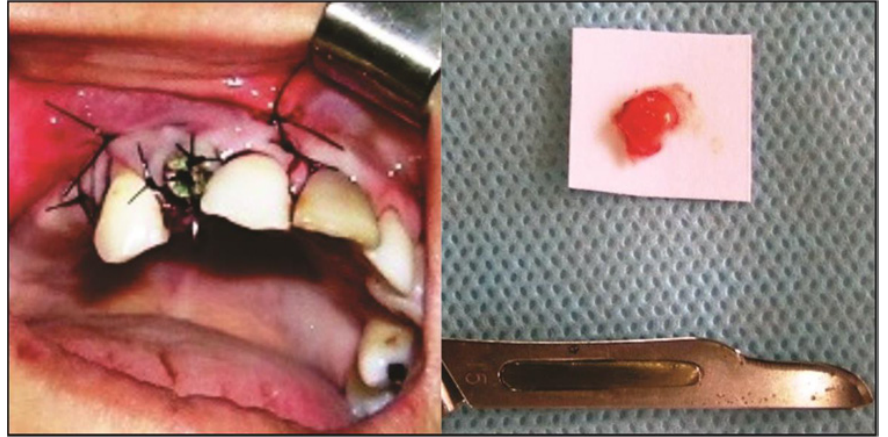

Figure 2 Clinical appearance and cystic epithelium after extraction of the element 12 and installation of device transalveolar decompression.

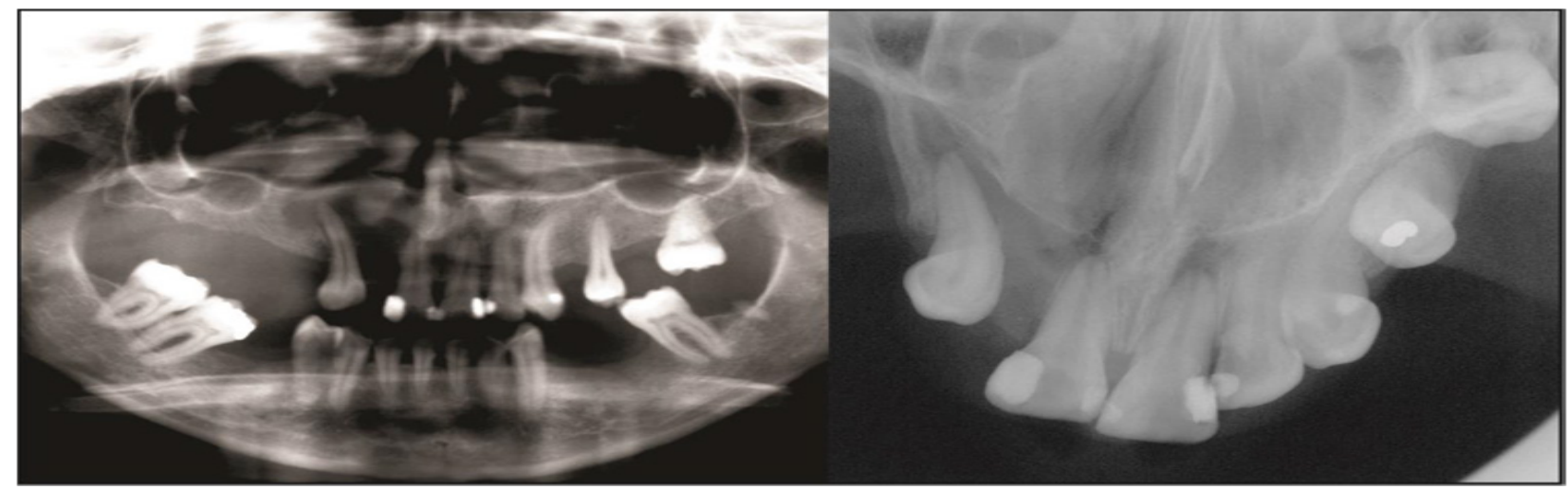

Figure 3 Panoramic and occlusal radiograph after 5 months of cystic decompression, showing bone formation.

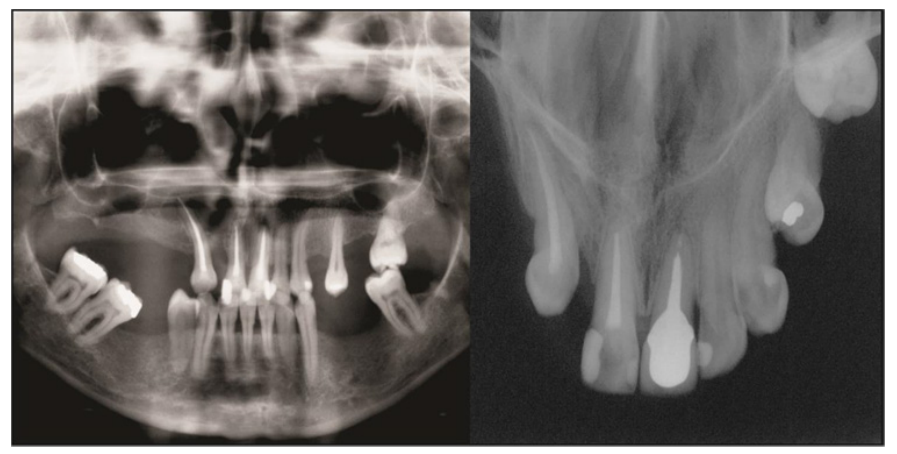

Figure 4 Panoramic and occlusal radiograph 13 months after starting treatment.

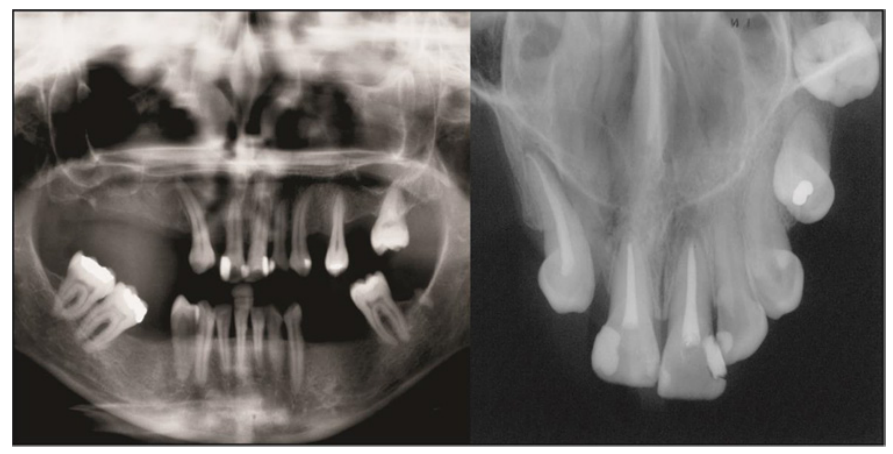

Figure 5 Panoramic and occlusal radiograph 19 months after the start of treatment, showing complete regression of the lesion.

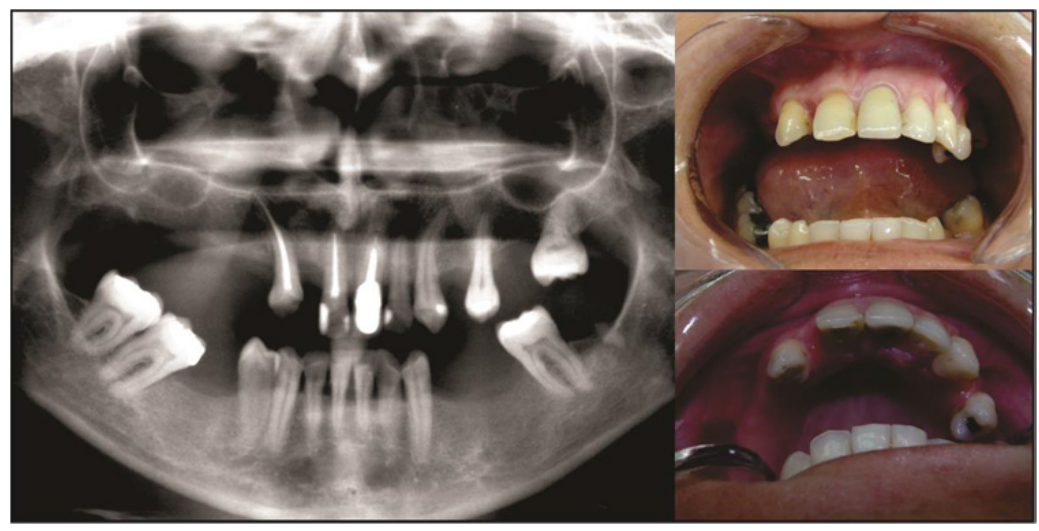

Figure 6 Panoramic radiograph and clinical appearance 60 months after start of treatment.

Citation: Marco RGD, Daroit NB, Conci RA, et al. Inflammatory periapical cyst decompression. case report with follow-up of five years.J Dent Health Oral Disord Ther. 2018;9(3): 190-192. DOI: I0.15406/jdhodt.2018.09.00376 


\section{Discussion}

Although small cystic lesions are usually healed by nonsurgical endodontic treatment, larger lesions may need additional treatment. Surgical enucleation of a cystic lesion can lead to damage of other teeth or anatomical structures. Therefore, treatment should start with the most conservative approach of decompression, to reduce the size of the lesion, and subsequently apicoectomy and cystectomy may be performed. ${ }^{5}$ Tandri, ${ }^{6}$ treated a case similarly, using a device to maintain decompression in a cystic lesion and endodontic treatment of the teeth involved. After 7 weeks the device was removed and irrigation at the site was continued, until closure of the cavity ( 2 weeks after removal of the drain). The control radiograph, 1 year after the treatment, showed bone neoformation and complete healing of the lesion.

Anavi et al. ${ }^{7}$ evaluated the stages of pre and post decompression with panoramic radiographs of 57 patients. In these, 73 odontogenic cysts were treated. The time of clinical decompression and data from histopathological exams were evaluated. Decompression reduced the area of the cyst on average $79.3 \%$. The result was good in $60 \%$ of cysts, moderate in $29 \%$, and poor in $11 \%$. Johann et al., ${ }^{8}$ performed treatment of an inflammatory radicular cyst, $25 \mathrm{~mm}$ in diameter, associated to a remainder of the root of tooth 65 in a 9year old. Removal of the remainder was performed, and afterwards a fragment of the cyst removed for the anatomopathological exam. Subsequently, a drain (resin tube) was installed through the socket, with the purpose of carrying out the cystic decompression. The parents were trained to periodically perform irrigations with $0.9 \%$ saline solution. After 6 months, radiographically, bone neoformation was observed, and the decompression device was removed. However, ten months later, there was recurrence of the lesion. A new decompression device was installed, which was removed after four months. After 5months, complete regression of the lesion was observed.

Delbem et al. ${ }^{9}$ reported the decompression of an inflammatory radicular cyst located on teeth 61 and 62 which caused displacement of tooth 21 , in a 5 year old, through a removable device (appliance) with a resin extension penetrating the cystic cavity. The resin was gradually worn down to ensure the eruption of tooth 21 . After 32 months, the central incisor erupted in the oral cavity and the radiolucent area could no longer be evidenced. Vasconcelos et al., ${ }^{10}$ performed the treatment of a large cystic lesion $(3.4 \times 3.2 \times 3.1 \mathrm{~cm})$, which involved teeth 11,12 and 13 (causing the spacing of their roots), by surgical decompression for four months. After this period there was a significant reduction of the lesion in all its extension, so enucleation of the cystic capsule was performed. In eight months of follow up there were no recurrences, and bone neoformation was observed.

\section{Final considerations}

1. Treatment of apical cystic lesions of great extent should be performed in the least invasive way possible. Thus, the cystic enucleation technique should be avoided in order to reduce risks and morbidity in the patient.
2. The decompression technique generates a high success rate with low morbidity and reduced loss of bone support, and should be the first choice of treatment for these lesions. However the patient's cooperation is essential so that the goals are achieved. We were successful using the transalveolar decompression technique, achieving complete healing of a previously established cystic lesion. This result was maintained during the five years of follow up.

\section{Acknowledgements}

None.

\section{Conflict of interest}

The authors declare that there is no conflict of interest.

\section{References}

1. Neville BW, Damm DD, Allen CM, et al. Patologia Oral \& Maxilofacial. In: Guanabara Koogan, editor. Rio de Janeiro; 2008.

2. Hupp JR, Ellis III E, Tucker MR. Cirurgia Oral e Maxilofacial Contemporânea. Elsevier: Rio de Janeiro; 2009.

3. Oztan MD. Endodontic treatment of teeth with a large periapical lesion. International Endodontic Journal. 2002;35(1):73-8.

4. Thoma KH. Oral surgery. $3^{\text {rd }}$ edn. St. Louis: Mosby;1958:1033-6.

5. Lagares DT, Egea JJS, Caballero AR, et al. Treatment of a Large Maxillary Cyst with Marsupialization, Decompression, Surgical Endodontic Therapy and Enucleation. J Can Dent Assoc. 2011;77:b87.

6. Tandri SB. Management of infected radicular cyst by surgical decompression. Journal of Conservative Dentistry. 2010;13(3):169-171.

7. Anavi Y, Gal G, Miron H, et al. Decompression of odontogenic cystic lesions: clinical long-term study of 73 cases. Oral Surg Oral Med Oral Pathol Oral Radiol Endod. 2011;112(2):164-169.

8. Johann ACBR, Gomes CO, Mesquita RA. Radicular Cyst: a case report treated with conservative therapy. JClin Pediatr Dent. 2006;31(1):14-15.

9. Delbem ACB, Cunha RF, Vieira AEM, et al. Conservative treatment of a radicular cyst in a 5-year-old child: a case report. International Journal of Paediatric Dentistry. 2003;13:447-450.

10. Vasconcelos RG, Queiroz LMG, Júnior LCA, et al. Abordagem Terapêutica em Cisto Radicular de Grandes Proporções - Relato de Caso. Revista Brasileira de Ciências da Saúde. 2012;16(3):467-474. 